\title{
Glass Wool Concentration Optimization for the Detection of Enveloped and Non-enveloped Waterborne Viruses
}

\author{
Albert Blanco ${ }^{1,2} \cdot$ Islem Abid ${ }^{3} \cdot$ Nawal Al-Otaibi ${ }^{3} \cdot$ Francisco José Pérez-Rodríguez $^{1,2} \cdot$ Cristina Fuentes $^{1,2}$. \\ Susana Guix ${ }^{1,2} \cdot$ Rosa M. Pintó ${ }^{1,2} \cdot$ Albert Bosch $^{1,2}$ (I)
}

Received: 26 July 2018 / Accepted: 13 March 2019 / Published online: 21 March 2019

○) Springer Science+Business Media, LLC, part of Springer Nature 2019

\begin{abstract}
An extremely affordable virus concentration method based on adsorption-elution to glass wool and subsequent reconcentration through polyethylene glycol 6000 (PEG) precipitation was optimized to recover not only non-enveloped viruses but also enveloped viruses. Hepatitis A virus (HAV) and transmissible gastroenteritis virus (TGEV) were employed as surrogates for naked and enveloped viruses, respectively, to set up the methodology. Initial experimentation in small-volume samples showed that both types of particles readily adsorbed to the positively charged glass wool but were poorly detached from it through standard elution with $0.05 \mathrm{M}$ glycine with 3\% of beef extract buffer, $\mathrm{pH} 9.5$, with elution efficiencies of $7.2 \%$ and $2.6 \%$, for HAV and TGEV, respectively. To improve the recovery of enveloped viruses, several modifications in the elution were assayed: increasing the elution $\mathrm{pH}$, extending glass wool and eluent contact time, adding a detergent, or performing the elution by recirculation or under agitation. Considering practicability and performance, recircularization of the eluent at $\mathrm{pH}$ 11.0 for 20 min was the elution procedure of choice, with efficiencies of $25.7 \%$ and $18.8 \%$ for HAV and TGEV in $50 \mathrm{~L}$ of water. Additionally, employing $20 \%$ PEG instead of $10 \%$ for virus reconcentration improved recoveries up to $47 \%$ and $51 \%$, respectively. The optimized procedure was applied to detect naturally occurring HAV and coronaviruses in surface water of Wadi Hanifa, Riyadh. HAV was detected in $38 \%$ of the samples, while one sample was positive for an alphacoronavirus. This cheap virus detection system enables the comprehensive surveillance of viruses present in water samples.
\end{abstract}

Keywords Water concentration $\cdot$ Coronavirus $\cdot$ Hepatitis A virus $\cdot$ Enveloped viruses $\cdot$ Non-enveloped viruses

\section{Introduction}

A large variety of pathogenic viruses found in the enteric tract of humans and animals may become environmental contaminants. Despite any virus susceptible to cause an infection after ingestion of water could be considered a

Albert Blanco and Islem Abid have contributed equally to this work.

Albert Bosch

abosch@ub.edu

1 Enteric Virus Laboratory, Department of Genetics, Microbiology and Statistics, University of Barcelona, Barcelona, Spain

2 Institute of Nutrition and Food Safety (INSA.UB), University of Barcelona, Barcelona, Spain

3 Botany and Microbiology Department, Science College, King Saud University, Riyadh, Saudi Arabia waterborne virus, most reported incidents of waterborne illness are actually related to gastroenteritis or hepatitis. The leading cause of gastroenteritis is norovirus (NoV), implicated in $20 \%$ of all cases worldwide, although other viruses such as rotaviruses, astroviruses, adenoviruses and sapoviruses have also been implicated in waterborne transmission of gastroenteritis (Bosch 2007). Regarding hepatitis, hepatitis A virus (HAV) is the foremost agent of acute hepatitis and waterborne hepatitis A outbreaks have been globally reported (Pintó et al. 2010), while hepatitis E virus is an emerging waterborne agent in the developing world, mostly by infection with genotype 1 virus, and much less frequently by genotype 2 virus (Kamar et al. 2014).

All the aforementioned viruses have in common that they occur in the environment as non-enveloped particles, implying a high virion stability (Sanchez and Bosch 2016). Nevertheless, some relevant enveloped pathogenic viruses are documented to be also found in the human gastrointestinal tract, among them coronaviruses $(\mathrm{CoV})$ that cause 
serious respiratory diseases such as the severe acute respiratory syndrome or SARS, reported in November 2002, with considerable shedding of the virus in stools (Chu et al. 2005). In fact, the environmental transmission of SARS was reported in a large, private apartment complex (McKinney et al. 2006). Another emerging CoV, the human Middle East Respiratory Syndrome coronavirus (MERS-CoV), initially reported in Saudi Arabia in 2012, is found in the urine and feces of infected animals (Dudas et al. 2018) and in human feces as well (Zhou et al. 2017; Drosten 2013). Other examples of enveloped viruses with potential waterborne spread are avian influenza viruses, such as the highly pathogenic H5N1. Despite their replication is primarily in the respiratory tract, avian influenza viruses induce a generalized infection in birds with actual replication in the gastrointestinal duct with abundant virus shedding in feces (Zhang et al. 2006; Worobey 2008).

$\mathrm{CoV}$ and influenza viruses have been reported to survive in the environment long enough to be potentially environmentally transmitted. For instance, both influenza A and B viruses survived for $24-48 \mathrm{~h}$ on hard, non-porous surfaces such as stainless steel and plastic but survived for less than 8-12 h on cloth, paper, and tissues (Bean et al. 1982). Studies on the survival of the $2009 \mathrm{H} 1 \mathrm{~N} 1$ pandemic virus in water evidenced the capacity of the virus to remain infectious for at least 200 days at $4{ }^{\circ} \mathrm{C}$ (Dublineau et al. 2011). Van Doremalen and coworkers (2013) ascertained the stability of MERS-CoV under different environmental conditions. MERS-CoV was more stable at low temperature/low humidity conditions and could still be recovered after $48 \mathrm{~h}$. During aerosolization of MERS-CoV, no decrease in stability was observed at $20{ }^{\circ} \mathrm{C}$ and $40 \%$ relative humidity. Another study employing infectious animal $\mathrm{CoV}$ as surrogates for human $\mathrm{CoV}$ pointed to their survival on surfaces for up to 28 days (Casanova et al. 2010).

Since viruses in water occur in very low numbers, processing of large volumes of water is required to concentrate the contaminant viruses in a much smaller final volume susceptible to be analyzed by molecular micro-methods (Ikner et al. 2012; Bosch et al. 2008). If this critical sample concentration step could be applied to concentrate not only non-enveloped viruses but enveloped viruses as well, it would provide a more comprehensive catchall virus detection system allowing a more comprehensive overview of the virome present in environmental water samples.

Positively charged glass wool filtration has been successfully employed for the concentration of non-enveloped viruses from water (Pérez-Sautu et al. 2012; Sano et al. 2011; Blanco et al. 2017). The aim of this study was to develop a procedure based on glass wool filtration for the recovery of enveloped and non-enveloped viruses from large volumes of water. Transmissible gastroenteritis virus (TGEV) and HAV were used as models for enveloped and non-enveloped viruses, respectively, for method optimization. Water from Wadi Hanifa in Riyadh, Saudi Arabia, was sampled for the presence of CoV and HAV following the selected methodology.

\section{Materials and Methods}

\section{Viruses and Cells}

Monolayers of ST cells (swine testis) were used to propagate the strain PUR46-MAD of the TGEV (Sanchez et al. 1990; Moreno et al. 2008), courtesy of L. Enjuanes and I. Sola, National Center of Biotechnology, Cantoblanco, Madrid). The PUR46-MAD strain of TGEV is attenuated, producing very mild or no enteritis and no mortality in conventional non-colostrum-deprived piglets, and absolutely no pathogenic at all for humans. TGEV was employed as a surrogate for not only human $\mathrm{CoV}$ such as MERS-CoV or SARS-CoV, but for generic enveloped viruses as well. ST (swine testis) cells grown in Eagle Minimum Essential Medium (MEM) with $10 \%$ fetal bovine serum (FBS) were infected at a multiplicity of infection (m.o.i.) of one, as described elsewhere (Bailey et al. 2004). Infected cell supernatants were collected and kept at $-80^{\circ} \mathrm{C}$. Cycles of freeze-thawing were avoided to prevent enveloped particle disruption. High-titer HAV stocks (strain HM175 43c) were produced in FRhK-4 cell monolayers grown in MEM with 15\% inactivated FBS, employing a m.o.i. of 1, and purified after lysing host cell membranes by the addition of a nonionic detergent $(1 \%$ NP-40) to the infected cell supernatants, as described elsewhere (Costafreda et al. 2014).

\section{Standard Waterborne Virus Concentration}

Initially, viruses were concentrated from water by filtration through positively charged glass wool (Ouest Isol, Alizay, France) as described elsewhere (Pérez-Sautu et al. 2012; Lambertini et al. 2008; Kiulia et al. 2010). To monitor the efficiency of virus concentration, TGEV and HAV were seeded at a concentration of $1.15 \times 10^{7}$ and $1.78 \times 10^{6}$ $\mathrm{TCID}_{50} / \mathrm{L}$, respectively, in 5 -L samples. Two consecutive elutions were performed by backcirculating $(5 \mathrm{~L} / \mathrm{min})$ through the glass wool $50 \mathrm{~mL}$ of $0.05 \mathrm{M}$ glycine with $3 \%$ of beef extract buffer (GBE), $\mathrm{pH} 9.5$ with the aid of a peristaltic pump (Millipore XX8200230) and recovering the eluates with the aid of a vacuum pump (Millipore, XX5522050). The resulting $100-\mathrm{mL}$ eluate was further concentrated by $10 \%$ polyethylene glycol 6000 (PEG) precipitation (Ueki et al. 2005). The pellet was resuspended in $5 \mathrm{~mL}$ of PBS, $\mathrm{pH} 7.4$, and stored at $-80^{\circ} \mathrm{C}$. 


\section{Optimization of the Concentration for the Recovery of Enveloped Viruses}

To improve the recoveries of enveloped viruses obtained with the standard glass wool filtration method, several steps of the elution procedure were modified and the effect of these changes on TGEV recovery ascertained. The tested modifications were: (i) increasing the $\mathrm{pH}$ of the elution buffer from 9.5 up to 11.0 , (ii) increasing the contact time of the glass wool and the GBE elution buffer from $10 \mathrm{~min}$ to overnight $(\mathrm{O} / \mathrm{N})$, (iii) adding detergent Tween 80 at a concentration of $0.3 \%$ in the elution buffer at $\mathrm{pH} 11.0$ and an $\mathrm{O} / \mathrm{N}$ contact time, (iv) unpacking the glass wool from the column, mixing it with the elution buffer at $\mathrm{pH} 11.0$ and keeping it under agitation $\mathrm{O} / \mathrm{N}$, and (v) recirculating the elution buffer at $\mathrm{pH} 11.0$ through the glass wool column for $1 \mathrm{~h}$ with a peristaltic pump (Millipore XX80EL004).

A first set of studies was performed in 5-L volumes, while a second set was performed with 50-L volumes. For virus reconcentration, PEG was employed at $10 \%$ and $20 \%$ concentrations to precipitate viruses in the eluates. For each procedure, three separate experiments were performed, and in each experiment, three separate replicas were seeded with the appropriate HAV and TGEV concentrations to yield final concentrations in the unconcentrated samples of around $9 \times 10^{5}$ and $6 \times 10^{6} \mathrm{TCID}_{50} / \mathrm{L}$, respectively. Virus recoveries were ascertained by quantitative TaqMan Real-Time-PCR (RT-qPCR) assays as described below.

\section{Quantitative Molecular Detection of TGEV Coronavirus}

RNA was extracted from $100 \mu \mathrm{L}$-aliquots of TGEV concentrates using the NucliSENS® miniMAG® extraction system (bioMérieux), according to the manufacturer's instructions. The extracted RNA was recovered in $100 \mu \mathrm{L}$ of the elution buffer.

A one-step RT-qPCR assay (RNA UltraSense ${ }^{\mathrm{TM}}$ OneStep Quantitative RT-PCR System, Invitrogen, Life Technologies) with previously described primers targeting the $S$ gene of the virus genome (Vemulapalli et al. 2009) was employed for quantitative TGEV detection. The final volume of reaction mixture was $25 \mu \mathrm{L}$, containing $0.4 \mu \mathrm{M}$ of forward primer (5'-TCTGCTGAAGGTGCTATTATATGC-3'), $1.2 \mu \mathrm{M}$ of reverse primer (5'-CCACAATTTGCCTCTGAA TTAGAAG-3'), $0.3 \mu \mathrm{M}$ of probe (5'FAM-C/TAAGGGCTC ACCACCTACTACCACCA-BHQ3') and $5 \mu \mathrm{L}$ of extracted RNA. The amplification parameters were as follows: reverse transcription at $50{ }^{\circ} \mathrm{C}$ for $30 \mathrm{~min}$ followed by denaturation at $95{ }^{\circ} \mathrm{C}$ for $15 \mathrm{~min}$. Then, 50 cycles of amplification were performed with each cycle, including denaturation at $94{ }^{\circ} \mathrm{C}$ for $15 \mathrm{~s}$, annealing for $30 \mathrm{~s}$ at $56{ }^{\circ} \mathrm{C}$ and extension for $15 \mathrm{~s}$ at $72{ }^{\circ} \mathrm{C}$.

\section{Molecular Detection of Wild-Type CoV}

A semi-nested TaqMan RT-PCR with previously described primers (Gouilh et al. 2011), targeting a conserved region of the RNA-dependent RNA-polymerase gene, was employed for the broad detection of wild-type alpha and beta CoV. The first PCR produces a 438-bp amplicon, whereas the nested one produces a 216-bp amplicon. Primer sequences were as follows: Primer reverse: 5'-CCATCRTCMGAHARAATC ATCATA-3'; Primer forward: 5'-GGTTGGGAYTAYCCW AARTGTGA-3'; Primer forward (2nd PCR): 5'-GCNAATWSTGTNTTTAACAT-3'. Briefly, the RT mix contained $200 \mu \mathrm{M}$ of dNTPs, $0.5 \mu \mathrm{M}$ of reverse primer and $5 \mu \mathrm{L}$ of RNA, using a final volume of $25 \mu \mathrm{L}$. The PCR and the semi-nested PCR mix contained $200 \mu \mathrm{M}$ of dNTPs, $1 \mu \mathrm{M}$ of both forward and reverse primer and $10 \mu \mathrm{L}$ of the reverse transcription product. The final volume of the PCR and the semi-nested PCR mix was $50 \mu \mathrm{L}$.

The amplification parameters were as follows: reverse transcription ran during $60 \mathrm{~min}$ at $42{ }^{\circ} \mathrm{C}$. The first PCR had a denaturation period of $95^{\circ} \mathrm{C}$ for $3 \mathrm{~min}$. Then, 30 cycles of amplification were performed with each cycle containing denaturation at $95{ }^{\circ} \mathrm{C}$ for $30 \mathrm{~s}$, annealing for $60 \mathrm{~s}$ at $50{ }^{\circ} \mathrm{C}$ and extension for $90 \mathrm{~s}$ at $72{ }^{\circ} \mathrm{C}$. There was a final elongation period of $7 \mathrm{~min}$ at $72{ }^{\circ} \mathrm{C}$. The second PCR had the same program as the first, but the elongation period run at $54{ }^{\circ} \mathrm{C}$ for $60 \mathrm{~s}$.

\section{Quantitative Molecular Detection of HAV}

HAV quantification was performed through a standardized one-step real-time TaqMan RT-qPCR (RNA UltraSense ${ }^{\text {TM }}$ One-Step Quantitative RT-PCR System, Invitrogen, Life Technologies) with primers HAV240 and HAV68, probe HAV150(-) labeled at the 5' with 6-carboxyfluorescein (FAM) and modified at the $3^{\prime}$ with the addition of a minor groove binder (MGB), and assay conditions described elsewhere (Costafreda et al. 2006) and specified in the ISO 15216-1:2017 standard for determination of hepatitis A virus and norovirus using real-time RT-qPCR (International Organization for Standardization - ISO 2017).

\section{Water Samples}

The collection of samples for field studies was carried out based according to ISO 19458:2006 (International Organization for Standardization - ISO 2006) for the collection of water samples for microbiological analysis. Seven $10-\mathrm{L}$ water samples were collected monthly from September to November 2015, from strategic sampling locations along the main channel of Wadi Hanifa in the Nejd region, Riyadh Province, in central Saudi Arabia. Samples were stored for a maximum of $24 \mathrm{~h}$ at $4{ }^{\circ} \mathrm{C}$ before being processed. Minimum 
and maximum temperature, conductivity and $\mathrm{pH}$ readings were $25-30{ }^{\circ} \mathrm{C}, 2604-5803 \mu \mathrm{S} / \mathrm{cm}$, and $7.4-7.8$, respectively. Total and fecal coliform counts (CFU) per $100 \mathrm{~mL}$ ranged from $1.5 \times 10^{4}$ to $1.7 \times 10^{5}$ and from $2.5 \times 10^{3}$ to $9.1 \times 10^{4}$, respectively.

\section{Sequencing}

Since our CoV RT-PCR detects all CoV belonging to either the alphacoronavirus or the betacoronavirus group, sequencing was necessary to characterize the positive samples. The DNA was sequenced using both forward and reverse primers using the thermo Sequenase Big Dye Terminator Cycle Sequencing Premix Kit (Amersham Pharmacia Biotech) on an automated sequencer (ABI PRISM 310). The nucleotide sequence was submitted to GenBank (accession number: KY565343).

Phylogenetic analysis was performed using the neighborjoining method (distance calculation by the Kimura-2-parameter correction; pairwise deletion) implemented in the MEGA7 program (Kumar et al. 2016), and results were validated by 1000 bootstrap replicates. Genotypes were assigned based on clustering with reference strains in the phylogenetic tree with $>70 \%$ bootstrap support.

\section{Statistical Analysis}

Data were ascertained to be normally distributed. Comparisons between means were performed using the student $t$ test (unpaired) using the IBM SPSS Statistics version 20 software (SPSS Inc., Chicago, IL, USA). P values $<0.05$ were considered statistically significant.

\section{Results}

\section{Method Optimization for Enveloped and Non-enveloped Virus Concentration from Water Through Glass Wool Filtration}

Table 1 depicts the recoveries of TGEV and HAV genome copies in the concentrates from 5-L samples. Initially, the standard glass wool filtration method, consisting of an adsorption to the positively charged glass wool matrix and subsequent elution with GBE buffer at pH, 9.5 after $10 \mathrm{~min}$ of contact, was employed. By this procedure, both viruses efficiently adsorbed onto the glass wool, with mean attachment efficiencies of $57.1 \%$ and $52.1 \%$, for TGEV and HAV, respectively, but then were poorly eluted from it, with recoveries of $2.6 \%$ and $7.2 \%$ for TGEV and HAV, respectively.

The elution efficiency dramatically increased when the $\mathrm{pH}$ of the eluent was raised to 11.0, irrespectively of other details of the procedure such as eluent contact time or the presence of Tween 80 (Table 1). In consequence, different elution procedures, all performed at $\mathrm{pH}$ 11.0, were assayed for the concentration of HAV and TGEV seeded in largevolume samples, such as $50-\mathrm{L}$ water samples (Table 2). Addition of Tween 80 hampers the recovery of TGEV, likely because of the presence of a lipid-containing envelope in the virion that is damaged by the detergent. Extending the elution time to overnight, or performing the elution under agitation or recircularization provided better efficiencies of recovery for both viruses. Considering both practicability and performance, recircularization of the eluent at $\mathrm{pH} 11.0$ for $20 \mathrm{~min}$ was the elution procedure of choice. The mean adsorption efficiencies for TGEV and HAV in $50 \mathrm{~L}$ of water were of $62 \%$ and $34 \%$ for TGEV and HAV, respectively.

PEG is widely employed for virus reconcentration from the eluates at a $10 \%$ concentration. By simply increasing the concentration of PEG from 10 to $20 \%$, a significant $(p<0.01)$ improvement in the efficiency of this
Table 1 Percent recoveries of transmissible gastroenteritis virus (TGEV) and hepatitis A virus (HAV) seeded in 5-L surface water samples employing adsorption onto glass wool and different elution procedures

\begin{tabular}{|c|c|c|c|c|}
\hline \multirow[t]{3}{*}{ Elution } & \multicolumn{4}{|l|}{ Virus } \\
\hline & \multicolumn{2}{|l|}{ TGEV } & \multicolumn{2}{|l|}{ HAV } \\
\hline & Adsorption & Elution & Adsorption & Elution \\
\hline $\mathrm{pH} 9.5 ; 10 \min ^{\mathrm{a}}$ & 71.6 & 2.6 & 59.6 & 7.2 \\
\hline $\mathrm{pH} 11.0 ; 10 \mathrm{~min}$ & 51.4 & 28.8 & 50.2 & 33.1 \\
\hline $\mathrm{pH} 11.0 ; \mathrm{O} / \mathrm{N}$ & 62.9 & 37.4 & 52.8 & 34.3 \\
\hline $\mathrm{pH} 11.0+$ Tween $800.3 \%$; O/N & 42.7 & 100.0 & 45.6 & 86.7 \\
\hline Average adsorption (mean $\pm S E)$ & $57.1 \pm 6.3$ & - & $52.1 \pm 2.9$ & - \\
\hline
\end{tabular}

The composition of the elution buffer was $0.05 \mathrm{M}$ glycine with 3\% of beef extract $O / N$ overnight, $S E$ standard error

${ }^{\text {a }}$ Standard elution procedure 
Table 2 Percent recoveries of transmissible gastroenteritis virus (TGEV) and hepatitis A virus (HAV) seeded in 50-L surface water samples employing adsorption onto glass wool and different elution procedures

\begin{tabular}{|c|c|c|c|c|}
\hline \multirow[t]{3}{*}{ Elution } & \multicolumn{4}{|l|}{ Virus } \\
\hline & \multicolumn{2}{|l|}{ TGEV } & \multicolumn{2}{|l|}{ HAV } \\
\hline & Adsorption & Elution & Adsorption & Elution \\
\hline $\mathrm{pH} 11.0 ; \mathrm{O} / \mathrm{N}$ & 73.8 & 2.9 & 44.1 & 6.8 \\
\hline pH 11.0+ Tween 80; O/N & 64.3 & 0.4 & 41.9 & 22.6 \\
\hline $\mathrm{pH}$ 11.0; agitation, $\mathrm{O} / \mathrm{N}$ & 50.1 & 10.4 & 23.2 & 23.3 \\
\hline $\mathrm{pH} 11.0$; recirculation $20 \mathrm{~min}$ & 59.2 & 18.0 & 27.1 & 23.9 \\
\hline Average adsorption $($ mean $\pm \mathrm{SE})$ & $61.9 \pm 9.9$ & & $34.1 \pm 10.5$ & \\
\hline
\end{tabular}

The composition of the elution buffer was $0.05 \mathrm{M}$ glycine with 3\% of beef extract

$O / N$ overnight, $S E$ standard error reconcentration step was observed. In this way, the efficiencies of recovery of TGEV and HAV increased from $30.8 \pm 14.7 \%$ to $51.3 \pm 10.5 \%$ and from $30.2 \pm 8.1 \%$ to $47.2 \pm 5.7 \%$, respectively (data not shown). Twenty percent PEG was employed thereafter as reconcentration procedure in the optimized concentration method.

Table 3 shows the efficiency of the different steps that compose the optimized concentration procedure for the detection of non-enveloped and enveloped viruses in large water volumes. TGEV was more efficiently $(\mathrm{p}<0.05)$ adsorbed onto the glass wool than HAV (62.8 vs $34.1 \%$ ); however, HAV was more readily eluted from the matrix than TGEV (25.7 vs $18.8 \%$ ), although this difference was not statistically significant. The efficiencies of virus precipitation by $20 \%$ PEG did not significantly differ among the enveloped and non-enveloped viruses: $41.9 \%$ for TGEV and 49.8\% for HAV. Altogether, the overall concentration efficiencies for TGEV and HAV were in the same range: $5.1 \%$ and $4.5 \%$ for TGEV and HAV, respectively. These recoveries for the enveloped and non-enveloped virus models were significantly $(\mathrm{p}<0.005)$ improved compared to those obtained employing the standard glass wool adsorption-elution procedure: $0.4 \%$ and $1.4 \%$ for TGEV and $\mathrm{HAV}$, respectively (Table 3 ).

\section{Molecular Detection of HAV and CoV in Environmental Samples from Saudi Arabia}

The optimized glass wool concentration procedure was applied for the detection of CoV and HAV naturally occurring in the surface water of Wadi Hanifa. Only one sample (Table 4) was positive by semi-nested RT-PCR for wild-type alpha/beta CoV. Sequence analysis evidenced that the $\mathrm{CoV}$ isolate was closely related to a novel rodent/shrew-specific clade within lineage A of genus Alphacoronavirus, reported in Asia and Europe, whose prototypic member is the recently described Lucheng virus found in China (Wang et al. 2015; Tsoleridis et al. 2016) (Fig. 1).

A standardized one-step RT-qPCR assay was employed for the quantitative detection of HAV in Wadi Hanifa
Table 3 Percent recoveries of transmissible gastroenteritis virus (TGEV) and hepatitis A virus (HAV) seeded in 50-L surface water samples employing the optimized concentration procedure

\begin{tabular}{lll}
\hline Concentration step & \multicolumn{2}{l}{ Virus recoveries } \\
\cline { 2 - 3 } & $\begin{array}{l}\text { TGEV } \\
(\text { mean } \pm \text { SD })\end{array}$ & $\begin{array}{l}\text { HAV } \\
(\text { mean } \pm \text { SD) }\end{array}$ \\
\hline Adsorption to glass wool & $62.8 \pm 3.5 \%$ & $34.1 \pm 3.6 \%$ \\
Elution from glass wool & $\left(3.6 \times 10^{6} \pm 2.6 \times 10^{5}\right)$ & $\left(3.0 \times 10^{5} \pm 3.7 \times 10^{4}\right)$ \\
Adsorption + Elution & $18.8 \pm 2.2 \%$ & $25.7 \pm 3.5 \%$ \\
PEG precipitation & $\left(6.8 \times 10^{5} \pm 1.2 \times 10^{5}\right)$ & $\left(7.8 \times 10^{4} \pm 2.2 \times 10^{4}\right)$ \\
Overall recovery & $11.8 \pm 2.1 \%$ & $8.8 \pm 2.2 \%$ \\
Recovery by standard procedure & $41.9 \pm 6.5 \%$ & $49.8 \pm 7.2 \%$ \\
\hline
\end{tabular}

Mean TGEV and HAV concentrations in the initial unconcentrated samples were $5.7 \times 10^{6} \pm 1.6 \times 10^{6}$, and $8.9 \times 10^{5} \pm 5.0 \times 10^{5} \mathrm{TCID}_{50} / \mathrm{L}$, respectively. Viruses were eluted by recirculating for $20 \mathrm{~min} 0.05 \mathrm{M}$ glycine buffer with $3 \%$ of beef extract at $\mathrm{pH} 11.0$, and further reconcentrated by precipitation with $20 \%$ polyethylene glycol 6000 (PEG). Mean virus titers $\left(\mathrm{TCID}_{50} / \mathrm{L}\right)$ recovered at each concentration step are shown in brackets 
Table 4 Detection of naturally occurring coronaviruses ( $\mathrm{CoV})$ and hepatitis A virus (HAV)

in surface water samples from

Wadi Hanifa, Saudi Arabia

(Sep-Nov, 2015)

\begin{tabular}{lllll}
\hline Month & CoV positivity & HAV positivity & $\begin{array}{l}\text { HAV Genome copies/L } \\
(\text { mean } \pm \text { SD })\end{array}$ & $\begin{array}{l}\text { HAV genome } \\
\text { copies/L (Range) }\end{array}$ \\
\hline Sep 2015 & $1 / 7(14 \%)$ & $5 / 7(71 \%)$ & $9.5 \times 10^{2} \pm 7.3 \times 10^{3}$ & $7.1 \times 10^{1}-1.9 \times 10^{4}$ \\
Oct 2015 & $0 / 7(0 \%)$ & $1 / 7(14 \%)$ & $5.0 \times 10^{1} \pm 0.0$ & $5.0 \times 10^{1}$ \\
Nov 2015 & $0 / 7(0 \%)$ & $2 / 7(29 \%)$ & $8.4 \times 10^{3} \pm 5.9 \times 10^{2}$ & $4.4 \times 10^{2}-1.6 \times 10^{3}$ \\
Total & $1 / 21(5 \%)$ & $8 / 21(38 \%)$ & $3.5 \times 10^{3} \pm 6.2 \times 10^{3}$ & $5.0 \times 10^{1}-1.9 \times 10^{4}$ \\
\hline
\end{tabular}

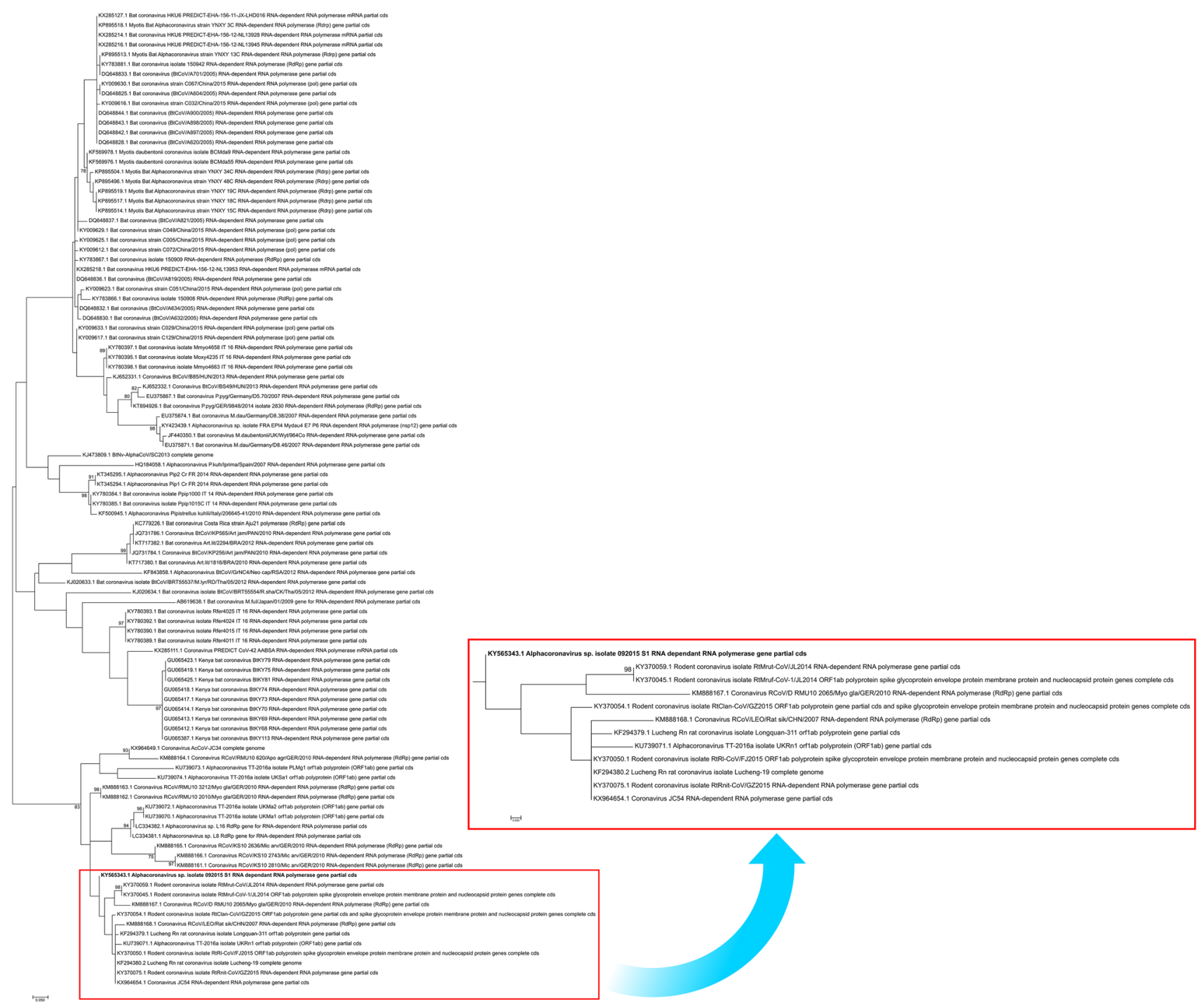

Fig. 1 Neighbor-joining phylogenetic tree of coronaviruses based on a conserved region of the RNA-dependent RNA-polymerase gene. Phylogenetic distances are expressed as the expected number of substitutions per nucleotide site and can be estimated using the scale. The numbers adjacent to the nodes represent the percentage of boot- strap support (of 1000 replicates) for the clusters to the right of the node. Only bootstrap values above $70 \%$ are shown. Bold type indicates the alpha coronavirus sequence obtained in this study (accession number: KY565343.1) 
waters (Table 4). HAV was detected in $38 \%$ of the samples $(8 / 21)$, and the highest positivity rate $(71 \%, 5 / 7)$ was observed in September. The mean genome copy number in the surface water was $3.5 \times 10^{3} / \mathrm{L}$, ranging from $5.0 \times 10^{1} / \mathrm{L}$ to $1.9 \times 10^{4} / \mathrm{L}$.

\section{Discussion}

The surveillance of the virological quality of water provides relevant inputs on the public health impact of waterborne viruses, among them, the incidence and behavior of viruses in the water environment, the assessment of the risk of infection posed by these waterborne viruses, or the efficiency of water treatments for virus removal/inactivation. Last but not least, characterization of the strains isolated from the water environment supplies valuable environmental epidemiology data that may provide a comprehensive overview of all viruses circulating in the community, encompassing not only viral agents causing symptomatic infections but also those that cause asymptomatic infections that otherwise remain unnoticed.

Positively charged oil-coated sodocalcic glass wool is a low-cost alternative for the concentration of different types of viruses in water without requiring any preconditioning of the sample (Gantzer et al. 1997; Lambertini et al. 2008; Kiulia et al. 2010; Sano et al. 2011; Pérez-Sautu et al. 2012; Blanco et al. 2017). Upon autoclaving, used glass wool may be readily disposed as recyclable waste. However, in our hands, the standard glass wool concentration method does not perform well for enveloped viruses and hence we adapted the procedure to concentrate enveloped viruses without dampening the recoveries of non-enveloped virus particles that remain the usual targets in environmental surveillance studies. By modifying the elution conditions, the recoveries of both types of viruses after glass wool concentration were dramatically improved, increasing from $7.2 \%$ and $2.6-25.7 \%$ and $18.8 \%$, for non-enveloped and enveloped viruses, respectively. An additional improvement in the virus concentration efficiencies was observed doubling the concentration of PEG, from 10 to $20 \%$, to perform the precipitation employed for virus reconcentration. In this way, $20 \%$ PEG provided increases in the recovery of non-enveloped and enveloped viruses of up to $56.3 \%$ and $66.6 \%$, respectively, compared to $10 \%$ PEG (data not shown).

The choice of PEG precipitation over other possible reconcentration options was also based on the affordability of the procedure in order to keep the cost of the entire virus concentration, i.e., glass wool adsorption/elution and PEG reconcentration, low enough (below 15 euro per sample) to be applicable for environmental surveillance studies performed in developing areas.
Current ISO standards for the molecular detection of viruses in water and food specify a threshold of acceptance of virus recovering efficiencies above $1 \%$ (International Organization for Standardization - ISO 2017; Lowther et al. 2017). This criterion is met for the recovery of nonenveloped and enveloped viruses from large volumes $(50 \mathrm{~L})$ of water employing glass wool filtration and PEG precipitation: $4.5 \%$ and $5.1 \%$, respectively. The combined adsorption-elution concentration steps provided recoveries of $8.8 \%$ and $11.8 \%$, respectively, for non-enveloped and enveloped viruses, from 50-L samples.

The optimized concentration methodology was applied for the detection of wild-type HAV, and alpha and beta $\mathrm{CoV}$, naturally occurring in the waters of the main channel of Wadi Hanifa, a valley running for $120 \mathrm{~km}$ from northwest to southeast, with several small-medium size towns, that crosses the city of Riyadh. HAV was detected in $38 \%$ of the samples $(8 / 21)$, while only one sample came out positive for a rat $\mathrm{CoV}$ belonging to lineage $\mathrm{A}$ of genus Alphacoronavirus, closely related to a $\mathrm{CoV}$ reported in European rats (Tsoleridis et al. 2016) that, together with the Lucheng virus described in China, form a distinct rodent/shrew-specific clade (Wang et al. 2015; Ge et al. 2017). The sole remit of the limited survey performed in Riyadh surface waters was to ascertain the validity of the concentration procedure for the comprehensive monitoring of the presence of non-enveloped and enveloped viruses in the environment. Noteworthy, the same methodology has enabled the very recent detection of alpha CoV, phylogenetically related to the one detected in Wadi Hanifa, in water samples from the metropolitan area of Barcelona (data not shown). No data exist on the potential zoonotic transmission of rodent $\mathrm{CoV}$ to humans.

At the end of June 2018, the burden of MERS in Saudi Arabia was 1853 laboratory-confirmed cases, including 717 related deaths with a case-fatality rate of $38.7 \%$ (WHO 2018). Although several $\mathrm{CoV}$ may be spread through the fecal-oral route, the potential waterborne transmission of MERS-CoV or SARS-CoV remains unlikely, despite the considerable shedding of both viruses in human stool (Chu et al. 2005; Drosten 2013) and, in the case of MERS-CoV, in camel stool too (Dudas et al. 2018). Nevertheless, there is evidence that environmental factors played an important role in the rapid spread of SARS infection throughout a large, private apartment complex (McKinney et al. 2006) and that the human gut may serve as an alternative infection route for MERS-CoV (Zhou et al. 2017).

Activities involving manipulation of samples potentially carrying MERS-CoV, SARS-CoV or other emerging agents may require BSL-3 facilities (CDC 2017). Raising the $\mathrm{pH}$ of the eluent employed in the glass wool virus concentration provided the dual benefit of significantly increasing virus recoveries for all types of viruses 
and, concomitantly, of greatly reducing virus infectivity, hence avoiding the need to work in sophisticated BSL-3 facilities.

\section{Conclusions}

A cheap and robust virus concentration procedure based on adsorption/elution onto glass wool and PEG precipitation that enables the comprehensive surveillance of viruses in large volumes of water has been developed. The methodology is able to concentrate non-enveloped as well as enveloped virus particles, opening the possibility to survey the presence in the environment of some health-significant enveloped viruses, such as MERS or SARS CoV, avian influenza virus, Nipah virus or Tick-borne encephalitis virus, among others. Although the waterborne transmission of these agents, if any, is negligible, their presence in the environment is indicative of their spread and prevalence among their human or animal hosts, even in the absence of symptomatic cases.

The affordability of the developed methodology makes it adequate for surveillance studies performed in low-income parts of the world.

Acknowledgements This project was funded in part by the National Plan for Science, Technology and Innovation (MAARIFAH), King Abdulaziz City for Science and Technology, Kingdom of Saudi Arabia, Award number (12-ENV2528-02), Food-FP7-311846 (European Union) and XRB-Biotechnology Reference Network (Generalitat de Catalunya). The funders had no role in study design, data collection and interpretation, or the decision to submit the work for publication.

\section{Compliance with Ethical Standards}

Conflict of interest The authors declare that they have no conflict of interest.

\section{References}

Bailey, M., Haverson, K., Miller, B., Jones, P., Sola, I., Enjuanes, L., et al. (2004). Effects of infection with transmissible gastroenteritis virus on concomitant immune responses to dietary and injected antigens. Clinical and Diagnostic Laboratory Immunology, 11(2), 337-343.

Bean, B., Moore, B. M., Sterner, B., Peterson, L. R., Gerding, D. N., \& Balfour, H. H. Jr. (1982). Survival of influenza viruses on environmental surfaces. The Journal of Infectious Diseases, 146(1), $47-51$.

Blanco, A., Guix, S., Fuster, N., Fuentes, C., Bartolome, R., Cornejo, T., et al. (2017). Norovirus in bottled water associated with gastroenteritis outbreak, Spain, 2016. Emerging Infectious Diseases, 23(9), 1531-1534. https://doi.org/10.3201/eid2309.161489.

Bosch, A. (2007). Human viruses in water. Perspectives in medical virology (Vol. 17, 1st ed ). Amsterdam: Elsevier.
Bosch, A., Guix, S., Sano, D., \& Pinto, R. M. (2008). New tools for the study and direct surveillance of viral pathogens in water. Current Opinion in Biotechnology, 19(3), 295-301.

Casanova, L. M., Jeon, S., Rutala, W. A., Weber, D. J., \& Sobsey, M. D. (2010). Effects of air temperature and relative humidity on coronavirus survival on surfaces. Applied and Environmental Microbiology, 76(9), 2712-2717.

CDC, Centers for Disease Control and Prevention (2017). Interim laboratory biosafety guidelines for handling and processing specimens associated with middle east respiratory syndrome coronavirus (MERS-CoV)-Version 2. https://www.cdc.gov/coronavirus/mers/ guidelines-lab-biosafety.html.

Chu, C. M., Cheng, V. C. C., Hung, I. F. N., Chan, K. S., Tang, B. S. F., Tsang, T. H. F., et al. (2005). Viral load distribution in SARS outbreak. Emerging Infectious Diseases, 11(12), 1882-1886.

Costafreda, M. I., Bosch, A., \& Pintó, R. M. (2006). Development, evaluation, and standardization of a real-time taqman reverse transcription-PCR assay for quantification of hepatitis A virus in clinical and shellfish samples. Applied and Environmental Microbiology, 72(6), 3846-3855.

Costafreda, M. I., Pérez-Rodriguez, F. J., D’Andrea, L., Guix, S., Ribes, E., Bosch, A., et al. (2014). Hepatitis A virus adaptation to cellular shutoff is driven by dynamic adjustments of codon usage and results in the selection of populations with altered capsids. Journal of Virology, 88(9), 5029-5041. https://doi.org/10.1128/ jvi.00087-14.

Drosten, C. (2013). Is MERS another SARS? The Lancet Infectious Diseases, 13(9), 727-728. https://doi.org/10.1016/S1473 -3099(13)70159-2 S1473-3099(13)70159-2 [pii].

Dublineau, A., Batéjat, C., Pinon, A., Burguière, A. M., Leclercq, I., \& Manuguerra, J.-C. (2011). Persistence of the 2009 Pandemic Influenza A (H1N1) virus in water and on non-porous surface. PLoS ONE, 6(11), e28043. https://doi.org/10.1371/journal.pone.00280 43.

Dudas, G., Carvalho, L. M., Rambaut, A., \& Bedford, T. (2018). MERS-CoV spillover at the camel-human interface. Elife, 7, e31257. https://doi.org/10.7554/eLife.31257.

Gantzer, C., Senouci, S., Maul, A., Levi, Y., \& Schwartzbrod, L. (1997). Enterovirus genomes in wastewater: concentration on glass wool and glass powder and detection by RT-PCR. Journal of Virological Methods, 65(2), 265-271.

Ge, X.-Y., Yang, W.-H., Zhou, J.-H., Li, B., Zhang, W., Shi, Z.-L., et al. (2017). Detection of alpha- and betacoronaviruses in rodents from Yunnan, China. Virology Journal, 14(1), 98. https://doi. org/10.1186/s12985-017-0766-9.

Gouilh, M. A., Puechmaille, S. J., Gonzalez, J.-P., Teeling, E., Kittayapong, P., \& Manuguerra, J.-C. (2011). SARS-Coronavirus ancestor's foot-prints in South-East Asian bat colonies and the refuge theory. Infection, Genetics and Evolution, 11(7), 1690-1702. https://doi.org/10.1016/j.meegid.2011.06.021.

Ikner, L. A., Gerba, C. P., \& Bright, K. R. (2012). Concentration and recovery of viruses from water: A comprehensive review. Food and Environmental Virology, 4(2), 41-67. https://doi.org/10.1007/ s12560-012-9080-2.

International Organization for Standardization - ISO, Geneva. (2006). Water quality -- Sampling for microbiological analysis. ISO 19458:2006 (pp. 18).

International Organization for Standardization - ISO, Geneva. (2017). Microbiology of the food chain - horizontal method for determination of hepatitis A virus and norovirus using real-time RT-PCR - Part 1: method for quantification. ISO 15216-1:2017. (pp. 31).

Kamar, N., Dalton, H. R., Abravanel, F., \& Izopet, J. (2014). Hepatitis E virus infection. Clinical Microbiology Reviews, 27(1), 116-138. https://doi.org/10.1128/cmr.00057-13.

Kiulia, N. M., Netshikweta, R., Page, N. A., van Zyl, W. B., Kiraithe, M. M., Nyachieo, A., et al. (2010). The detection of enteric 
viruses in selected urban and rural river water and sewage in Kenya, with special reference to rotaviruses. Journal of Applied Microbiology, 109(3), 818-828.

Kumar, S., Stecher, G., \& Tamura, K. (2016). MEGA7: Molecular evolutionary genetics analysis version 7.0 for bigger datasets. Molecular Biology and Evolution. 33(7), 1870-1874, https://doi. org/10.1093/molbev/msw054msw054 [pii].

Lambertini, E., Spencer, S. K., Bertz, P. D., Loge, F. J., Kieke, B. A., \& Borchardt, M. A. (2008). Concentration of enteroviruses, adenoviruses, and noroviruses from drinking water by use of glass wool filters. Applied and Environmental Microbiology, 74(10), 2990-2996.

Lowther, J. A., Bosch, A., Butot, S., Ollivier, J., Mäde, D., Rutjes, S. A., et al. (2017). Validation of ISO method 15216 part 1 - Quantification of hepatitis A virus and norovirus in food matrices. International Journal of Food Microbiology. https://doi.org/10.1016/j. ijfoodmicro.2017.11.014.

McKinney, K. R., Gong, Y. Y., \& Lewis, T. G. (2006). Environmental transmission of SARS at Amoy Gardens. Journal of Environmental Health, 68(9), 26.

Moreno, J. L., Zuniga, S., Enjuanes, L., \& Sola, I. (2008). Identification of a coronavirus transcription enhancer. Journal of Virology, 82(8), 3882-3893. https://doi.org/10.1128/JVI.02622-07JVI $.02622-07 \% 5$ Bpii\%5D.

Pérez-Sautu, U., Sano, D., Guix, S., Kasimir, G., Pintó, R. M., \& Bosch, A. (2012). Human norovirus occurrence and diversity in the Llobregat river catchment, Spain. Environmental Microbiology, 14(2), 494-502. https://doi.org/10.1111/j.1462-2920.2011.02642 .X.

Pintó, R. M., Costafreda, M. I., Perez Rodriguez, F. J., D.'Andrea, L., $\&$ Bosch, A. (2010). Hepatitis A virus: State of the art. Food and Environmental Virology, 2(3), 127-135.

Sanchez, C. M., Jimenez, G., Laviada, M. D., Correa, I., Sune, C., Bullido, M., et al. (1990). Antigenic homology among coronaviruses related to transmissible gastroenteritis virus. Virology, 174(2), 410-417.

Sanchez, G., \& Bosch, A. (2016). Survival of enteric viruses in the environment and food. In S. M. C. Goyal, J.L; (Ed.), Viruses in foods. Food Microbiology (2 edn., pp. 367-392). New York: Springer.

Sano, D., Perez-Sautu, U., Guix, S., Pinto, R. M., Miura, T., Okabe, S., et al. (2011). Quantification and genotyping of human sapoviruses in the llobregat River Catchment, Spain. Applied and Environmental Microbiology, 77(3), 1111-1114.

Tsoleridis, T., Onianwa, O., Horncastle, E., Dayman, E., Zhu, M., Danjittrong, T., et al. (2016). Discovery of Novel Alphacoronaviruses in European Rodents and Shrews. Viruses, 8(3), 84. https://doi. org/10.3390/v8030084.

Ueki, Y., Sano, D., Watanabe, T., Akiyama, K., \& Omura, T. (2005). Norovirus pathway in water environment estimated by genetic analysis of strains from patients of gastroenteritis, sewage, treated wastewater, river water and oysters. Water Research, 39(18), 4271-4280. https://doi.org/10.1016/j.watres.2005.06.035. pii].

van Doremalen, N., Bushmaker, T., \& Munster, V. J. (2013). Stability of Middle East respiratory syndrome coronavirus (MERS-CoV) under different environmental conditions. EuroSurveillance, 18(38), 20590.

Vemulapalli, R., Gulani, J., \& Santrich, C. (2009). A real-time TaqMan RT-PCR assay with an internal amplification control for rapid detection of transmissible gastroenteritis virus in swine fecal samples. Journal of Virological Methods, 162(1-2), 231-235. https ://doi.org/10.1016/j.jviromet.2009.08.016S0166-0934(09)00393 $-0 \% 5$ Bpii\% $5 \mathrm{D}$.

Wang, W., Lin, X.-D., Guo, W.-P., Zhou, R.-H., Wang, M.-R., Wang, C.-Q., et al. (2015). Discovery, diversity and evolution of novel coronaviruses sampled from rodents in China. Virology, 474, 19-27. https://doi.org/10.1016/j.virol.2014.10.017.

WHO, World Health Organization (2018). MERS situation update. http://www.emro.who.int/pandemic-epidemic-diseases/mers-cov/ mers-situation-update-june-2018.html.

Worobey, M. (2008). Phylogenetic evidence against evolutionary stasis and natural abiotic reservoirs of influenza A virus. The Journal of Virology, 82(7), 3769-3774.

Zhang, G., Shoham, D., Gilichinsky, D., Davydov, S., Castello, J. D., \& Rogers, S. O. (2006). Evidence of influenza A virus RNA in Siberian lake ice. Journal of Virology, 80(24), 12229-12235.

Zhou, J., Li, C., Zhao, G., Chu, H., Wang, D., Yan, H. H.-N., et al. (2017). Human intestinal tract serves as an alternative infection route for Middle East respiratory syndrome coronavirus. Science Advances. https://doi.org/10.1126/sciadv.aao4966.

Publisher's Note Springer Nature remains neutral with regard to jurisdictional claims in published maps and institutional affiliations. 